\title{
THE PENN WAMPUM BELTS
}

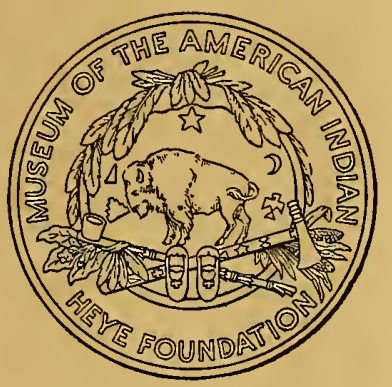

LEAFLETS OF THE

MUSEUM OF THE AMERICAN INDIAN HEYE FOUNDATION, NEW YORK NUMBER $4, \quad, \quad, \quad$ MARCH 22, 1925 


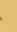





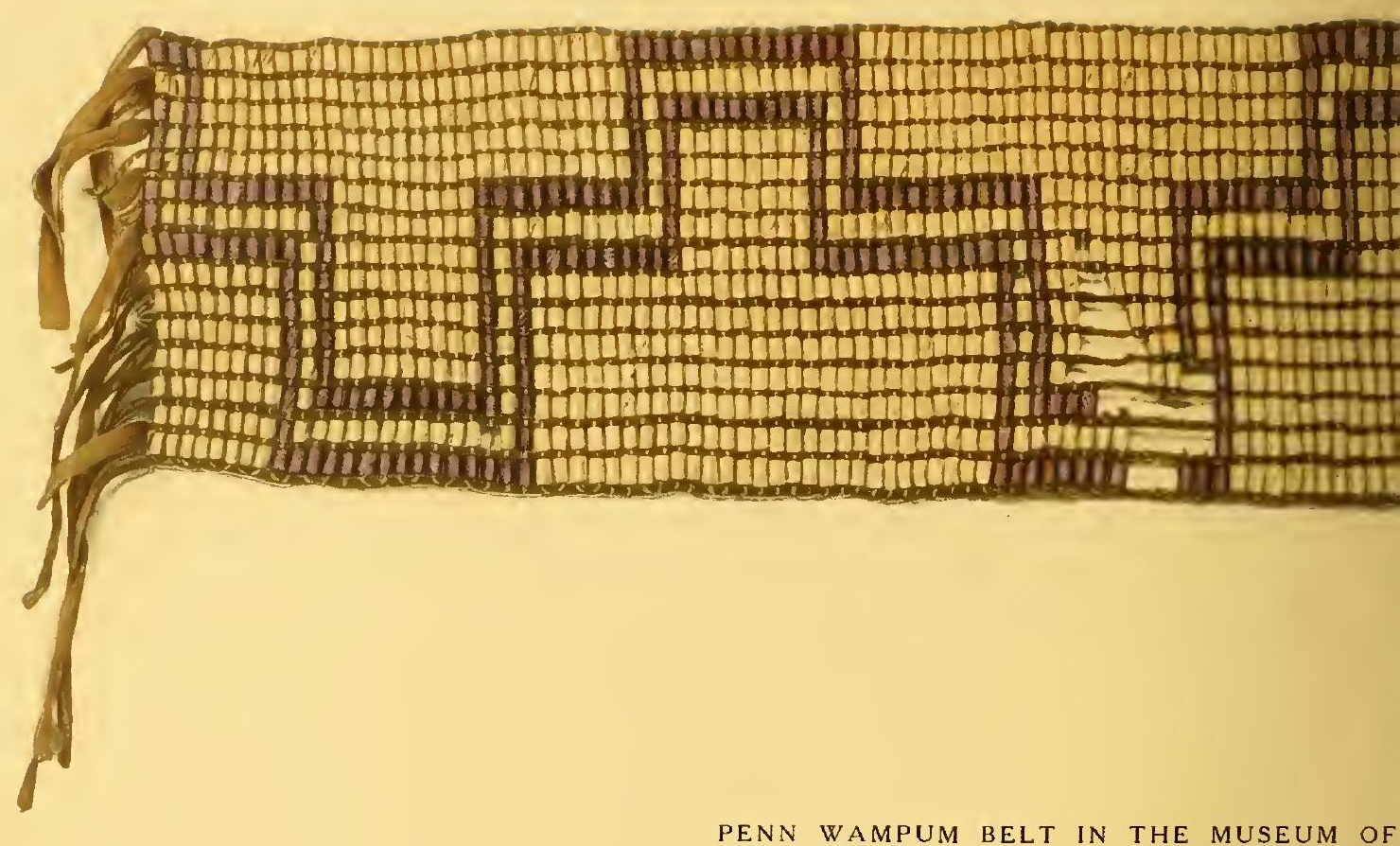




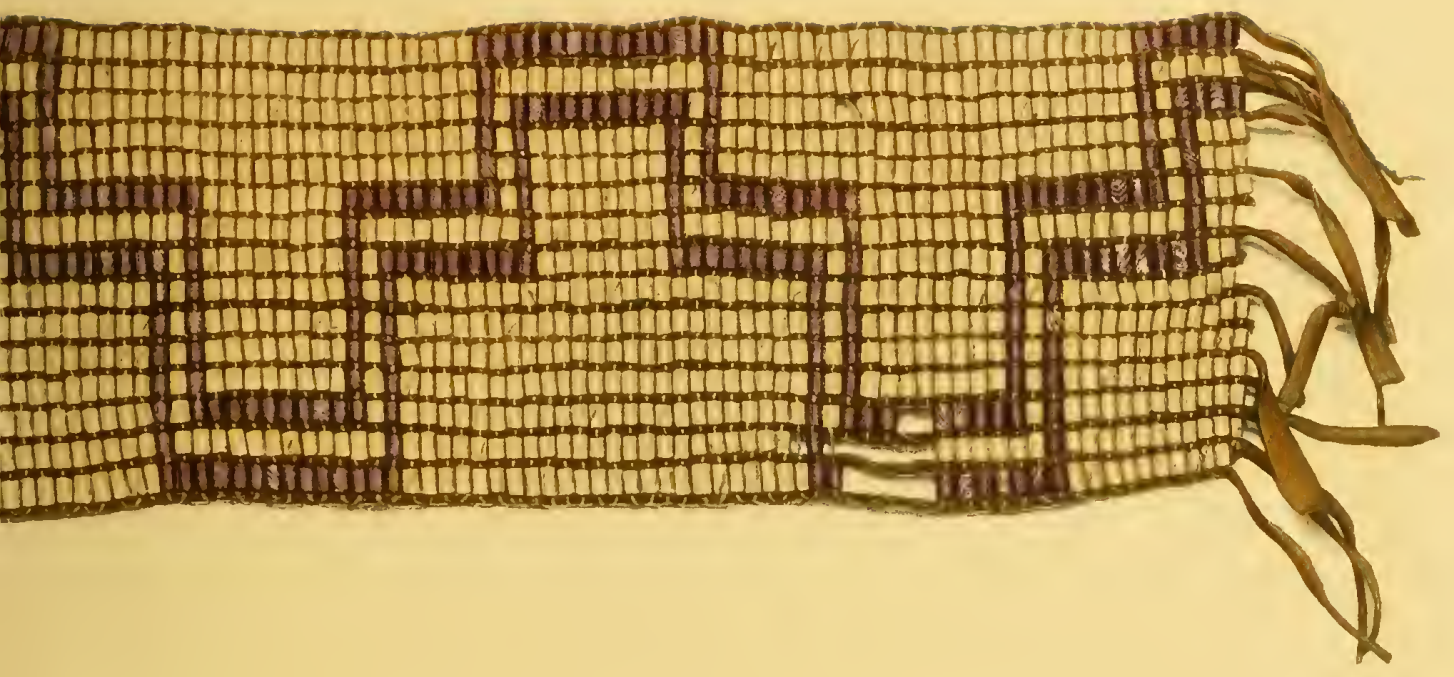

AMERICAN INDIAN, HEYE FOUNDATION 



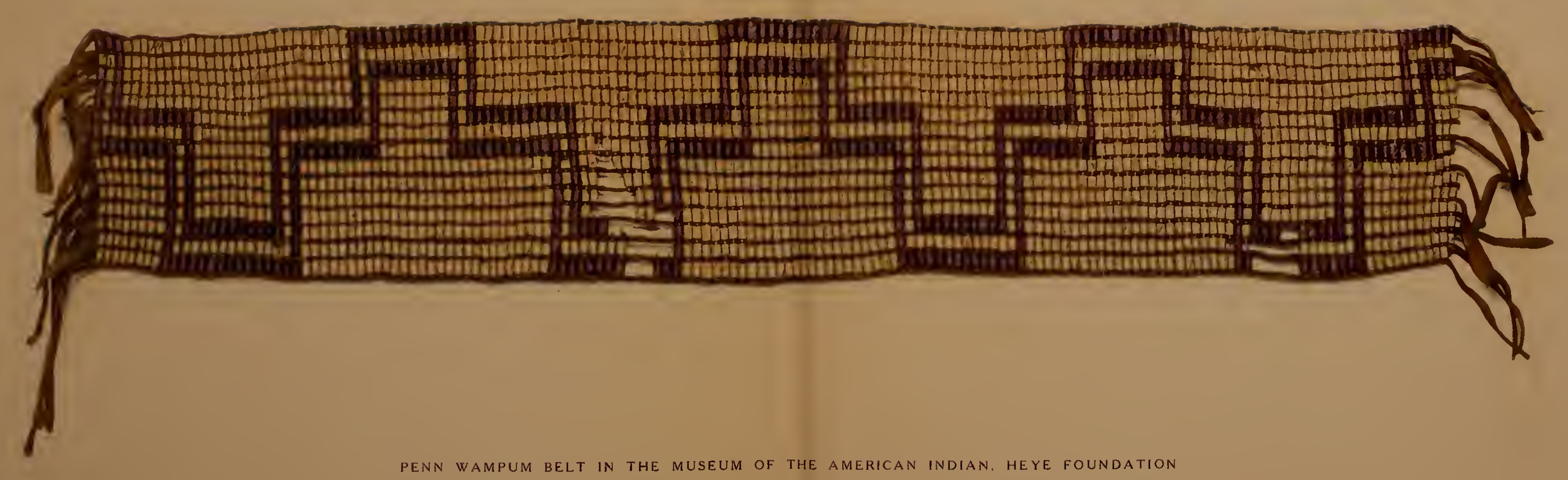







\section{THE PENN WAMPUM BELTS}

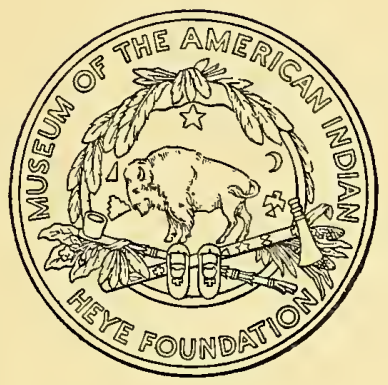

LEAFLETS OF THE

MUSEUM OF THE AMERICAN INDIAN HEYE FOUNDATION, NEW YORK NUMBER $4, \quad, \quad, \quad$ MARCH 22, 1925 

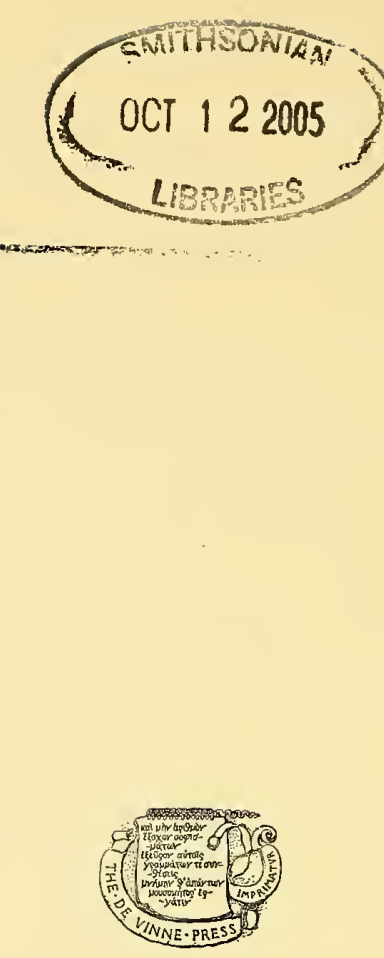
To

\section{HARMON WASHINGTON HENDRICKS}

WHOSE BENEFICENCE IN BEHALF OF THE MUSEUM OF THE AMERICAN INDIAN, HEYE FOUNDATION, HAS BEEN THE MEANS OF ENABLING THE MUSEUM TO BRING MANY OF ITS ACTIVITIES TO FRUITION, THIS LEAFLET IS DEDICATED BY ITS BOARD OF TRUSTEES IN COMMEMORATION OF HIS SEVENTY-NINTH ANNIVERSARY.

NEW YORK, MARCH 22, 1925 



\title{
FOREWORD
}

\begin{abstract}
$A$
FEW years ago there appeared in the daily press of $\mathrm{New}$ York a brief paragraph announcing the fact that there had been sold at public auction in London a number of objects belonging to the Penn family, including two wampum belts that William Penn had received from the Indians while negotiating for the transfer of lands in what is now the State of Pennsylvania. Mrs. Thea Heye, who noticed the announcement, brought it to the attention of Mr. Harmon W. Hendricks, Vice-President of the Museum of the American Indian, Heye Foundation, who, recognizing the historical and ethnological value of the belts, determined that they should be deposited for permanent preservation in the Museum. Mr. Hendricks therefore immediately notified his London representative to trace the purchaser of the belts and to employ every effort to procure them. After long and tedious negotiation the belts were obtained and duly presented by Mr. Hendricks to the Museum.

In view of the great rarity and value of such early objects as the Penn belts, it is fitting that one of the Leaflets of the Museum should be devoted to a description of them; and it is especially appropriate that the publication should be dedicated to Mr. Hendricks as a slight measure of recognition not alone of the valued gift which forms the subject of this work, but of his outstanding generosity in behalf of the Museum from the time of its inception.
\end{abstract}

GeORge G. HeYe, Director 



\section{The Penn Wampum Belts}

The [Narragansett] Indians are ignorant of Europes Coyne; yet they have given a name to ours, and call it Monèsh from the English money. Their owne is of two sorts; one white, which they make of the stem or stocke of the Periwincle, which they call, Meteauthock, when all the shell is broken off : and of this sort six of their small Beads (which they make with holes to string the bracelets) are currant with the English for a Peny. The second is black. inclining to blew, which is made of the shell of a fish, which some English call Hens, Poquaûhock, and of this sort three make an English peny They that live upon the Sea side generally make of it, and as many make as will.

Roger Williams, 1643

F THE many negotiations between William Penn and the Indians of Pennsylvania, concerning the transfer of land as well as those of a political nature, there exist few memorials at the present time. We do not refer to the records of land purchase written by the English, of which many are preserved in the archives of the State, but to the autographic documents of the natives, the Delawares and the Six Nations. These, in the form of wampum belts, are known to have been made and used in Colonial times by the eastern Indians as documents of authority and faith in recording transactions among themselves and with the whites. Notwithstanding their legal importance in the period denoted, and their ethnic historic value, which has risen by progressive advance since that time, the abundant wampum documents of the period have not survived together with their meanings and applications, either among the English or the Indians. Since it is well known that the eastern Indians kept records in the form of wampum belts, which were held in the possession of chiefs and councils to remind them of their agreement with the whites, there is little need to review in detail the elaborate wampum ceremonies and council life of the Iroquois and the Delawares at this time. The purpose of our paper is to present certain information appertaining to some most interesting wampum belts acquired in England a few years ago and now preserved in the Museum of the American Indian, Heye Foundation.

Until the present time there has been known at large only the one authentic wampum belt remaining in the hands of the English 


\section{THE PENN WAMPUM BELTS}

to commemorate the long series of negotiations between the Colonial proprietors of Pennsylvania and the Delaware Indians. This is the famous Penn Treaty belt ( $\mathrm{pl}$. III), a relic of wide fame in American history; one reproduced and referred to in numerous compilations by historians, and by politicians, as representing that verbal compact between the Quakers and the Indians which has now become a byword in the country - "the treaty never made and never broken." There exist, however, no documentary grounds enabling the belt to be dated, and nothing whatsoever to explain the circumstance of its possession in the Penn family, nor to point out its connection with any specific event recorded in the history of the Colony. Records, moreover, fail to yield mention of any speeches which may be supposed to have accompanied it, as well as explanations of the symbols which appear on its surface. Unfortunately, then, this belt stands as an isolated relic, to be interpreted, now that it is torn from its ceremonial setting, as the imagination may suggest. No native interpretation of its symbolism even has been hitherto sought. And so its meaning rests solely upon what appears to be the idea of friendship, indicated by the two human outlines affectionately holding hands. As such this interesting and impressive memorial stands again as a document unaffixed to any known event. The circumstances making it necessary to state this about so famous and valuable a document may naturally seem regrettable. And even more so is the fact that other belts known by historical reference to have been placed in the hands of Colonial authorities by emissaries of the eastern tribes have neither been kept in the colony, nor is their whereabouts known. One may well wonder what has become of the thirty-two belts of wampum exhibited by the Delawares to the Governor of Pennsylvania about the middle of the eighteenth century, on the occasion of a call upon him on their way to Onondaga. No other belts were even known to be in existence from any source as early as that attributed to the Penn wampum belt until the opportunity arrived for Mr. Hendricks to acquire for the Museum of the American Indian, Heye Foundation, two more belts whose derivation is undoubtedly from the same source. These constitute the 


\section{THE PENN WAMPUM BELTS}

subject matter of the study which we were invited to make. The outcome is forthwith presented in this paper-the feeble attempt at so late a date, when the associations have been forgotten, to bring them forth as memorials, in a double sense.

The general tradition associated with these two later Penn belts seems to coincide with that of the first treaty belt previously mentioned. The three belts may accordingly be regarded as a group of documents in close relationship with one another from the time they were first placed in the hands of the Penn family. How they reached the hands of Penn is unknown. The general belief, which has been repeated by several authorities, is that the first belt was the original object delivered by the Delawares to Penn at the memorable treaty under the elm at Shackamaxon in I682. In his memoir on Iroquois wampum, Beauchamp* presents the consensus of thought regarding this belt as having come into possession of the founder of Pennsylvania at some one of his treaties with the tribes occupying the province ceded to him. In the catalogue of paintings and other objects of interest belonging to the Historical Society of Pennsylvania, published in 1872 (page 54), the note of entry simply mentions that in 1857 this belt was given to the Society by Granville John Penn, great-grandson of William Penn. The statement is attributed to the donor that it was supposed to have been given to William Penn at the Treaty of Shackamaxon. Beauchamp refers to this tradition, but wisely expresses his skepticism as to its accuracy. Considerable doubt has been raised over the correctness of the tradition in general, and since there is no source of verification upon which to ascribe either the first treaty belt or the two now to be described, we must for the present simply regard the three as memorials undocumented in history.

We are indebted to Mr. Albert Cook Myers, of the Historical Society of Pennsylvania, for his kindness in allowing us to draw on his profound knowledge of the Penn documents, enabling us to

*Beauchamp, Wm. M., Wampum and Shell Articles used by The New York Indians, Bull. 41, New York State Museum, Albany, 1901. 


\section{THE PENN WAMPUM BELTS}

shorten our task of research amid the voluminous records, and to avoid errors and omissions in searching out possible connections between known documents and the wampum belts.

In view of the fact that nothing tangible can be elicited from extant records regarding these interesting belts, we are left to find other sources to furnish testimony as to their possible meaning. Fortunately the Six Nations of the Iroquois still form a national body, though sorely oppressed by a Government policy as antagonistic today as any which they have had to resist in the past, either by arms, by wit, or by tongue. Turning to them for assistance in the hope of gaining some knowledge of the meaning of the signs and symbols inscribed on the belts, we at least gain some light, fragmentary as it is. In January, 1925, a visit was made, under the auspices of the Museum, to the council of the Six Nations on the Grand River Reserve near Brantford, Ontario. Photographs in natural size of the two belts were shown to the chiefs of the Six Nations and a print of the historic Penn treaty belt, herein reproduced, was likewise submitted to them for examination and interpretation, if such were possible. It may be noted in this connection that until recently the Six Nations have retained in their possession a number of wampum belts, and have laudably kept alive the tradition of their decipherment in the inner recesses of their esoteric life. Fortunately, indeed, Chief David Sky, an Onondaga, and Chief David Seneca Hill, who holds a Cayuga chieftainship, were of a disposition to render their able services in the task of explanation. The circumstances of the visit and the manner of procedure in securing this information need not be rehearsed here, since they belong to a topic embracing the political life of the Iroquois. The results of our conference, however, were as follows:

The first belt to be dealt with (pl. I) may be referred to as the "Freedom" belt. In this we find the lines to be a geometrical meander, consisting of parallel dark lines, enclosing a white one, effected on a white background. To this striking symbol Chief Sky assigned a meaning which, to his mind, was definite and expressed without hesitation, "the freedom of the Indian." The explanation followed, that

$$
\text { [I0] }
$$




\section{THE PENN WAMPUM BELTS}

when the belt was given to the Colonial representative the figure indicated that, even though the land may have changed ownership, the Indians reserved the right to traverse its surface wherever they wished in pursuit of what they needed. The dark lines of the pattern represent the paths of the Indians to and fro, which were to be pursued in freedom by them after its cession. Chief Hill had previously explained his idea of this figure as representing "paths in territories which had been sold," his opinion thus coinciding approximately with that of Chief Sky. Both independently stated that the white background symbolized the "parchment" of documents functioning as legal instruments among the whites. The interesting interpretation given by these chiefs is highly plausible, for it may be observed that in all transactions between the natives and Europeans the retention of the privilege of free passage over the ceded land was characteristic of the Indian idea of "sale." It was over this same assumption that so many disputes arose in connection with the interpretation of title rights. For, especially among the Algonkian, when land sales were made to the whites, the Indians seldom imagined that the usufruct would be denied them, provided this did not interfere with the enterprises of the purchaser. And we may add that in more than one case, when land was transferred, the natives thought the title would terminate with the death of the purchaser. This aspect toward land sales is still prevalent among the Algonkian of the North, seeming to embody an idea which is inseparable from the liberty-loving mind of the hunting nomad.

In the second belt of the group (pl. II) we observe a series of four cruciform figures in black, ranged side by side. In the open white interiors are simple crosses in dark beads. The foundation of the belt is white. Both informants agreed that here again the white represented "parchment." But, with characteristic reserve, Chief Sky declined to express his opinion of the meaning of the symbols. He regarded the emblem for some minutes in silence, without vouchsafing any suggestion at the conclusion of his scrutiny. Some hours before, however, Chief Hill had given his opinion that the four enclosures represented territories to which the belt had reference. 


\section{THE PENN WAMPUM BELTS}

$\mathrm{He}$, too, showed some hesitation and reserve in expressing his idea of its meaning. The reserve evinced by both informants in the same way on the same subjects, without having an opportunity to consult each other, impressed one with the sincerity and seriousness of their expressions. Aside from native authority as to the significance of the figures, it may be noted that parallelograms of this type appear on other wampum belts, and have received interpretations which do not always coincide. In some cases the analogous meanings of "tribes," or "castles," some referring to "the strongholds" of tribes, have been noted. Having no anterior authority for checking or correcting the several views expressed, we can do no more at present, it seems, than to place them on record.

Several general remarks of importance concerning these belts were added by Chief Sky. He asserted that from their appearance they were complete belts and not fragments. Furthermore, he explained that the barely visible evidences of an application of red ocher to the surface and strings of the second belt were to be regarded as a representation of the national "emblem" of the Indian; that when the Indian applied his color to an object it was in the form of rouge, and at the same time it served as a chemical preservative.

We now come to the consideration of the famous Treaty Belt in possession of the Historical Society of Pennsylvania, which, as we have shown, may be regarded as one of the original group of three obtained by the Penns, or their deputy governors, from the Indians of Pennsylvania. When shown the photograph of this belt, the same remarks about the white background were made by both informants. The two figures near the center of the belt were independently indicated to be those of a white man and an Indian. The clasped hands were explained as an indication, on the part of the natives, of a desire for amity. Hitherto those who have mentioned this belt, and some who have written about it, have asserted the larger figure to be a representation of the white man and the smaller that of an Indian. The projection of two dark beads on the head of the larger figure on the right has been invariably designated by redactors as representing the white man's hat. But on this point the testimony of the two 



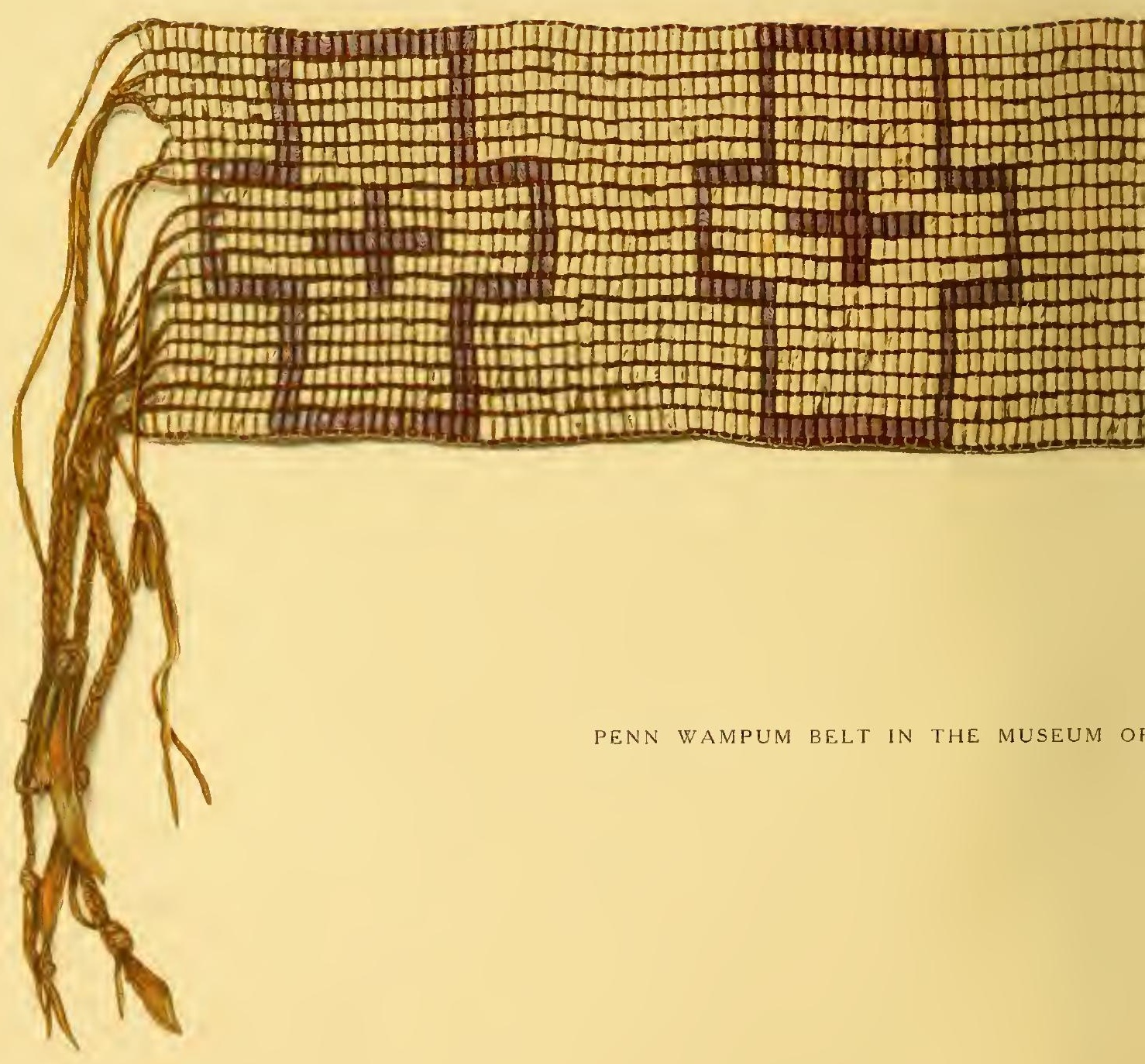




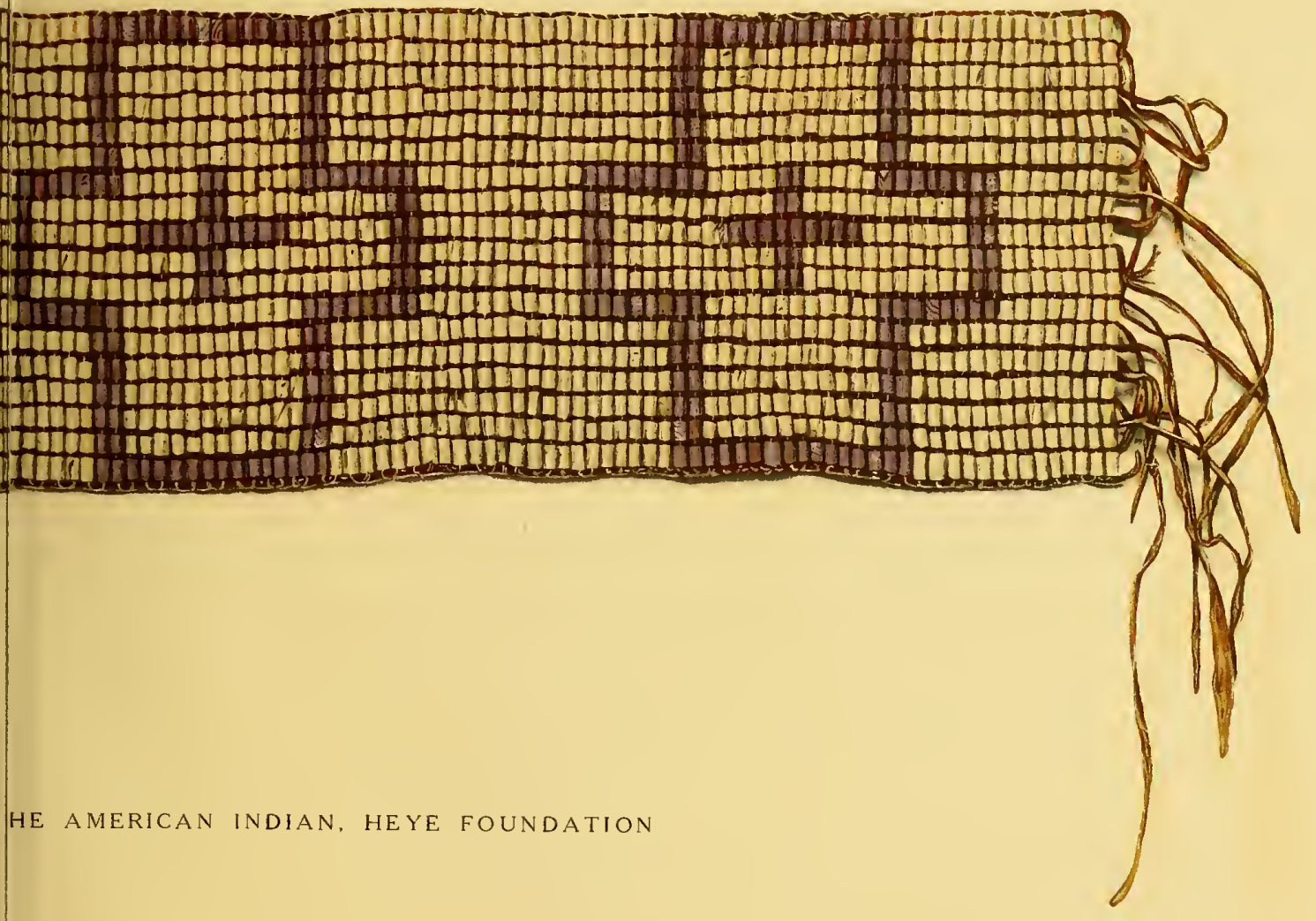





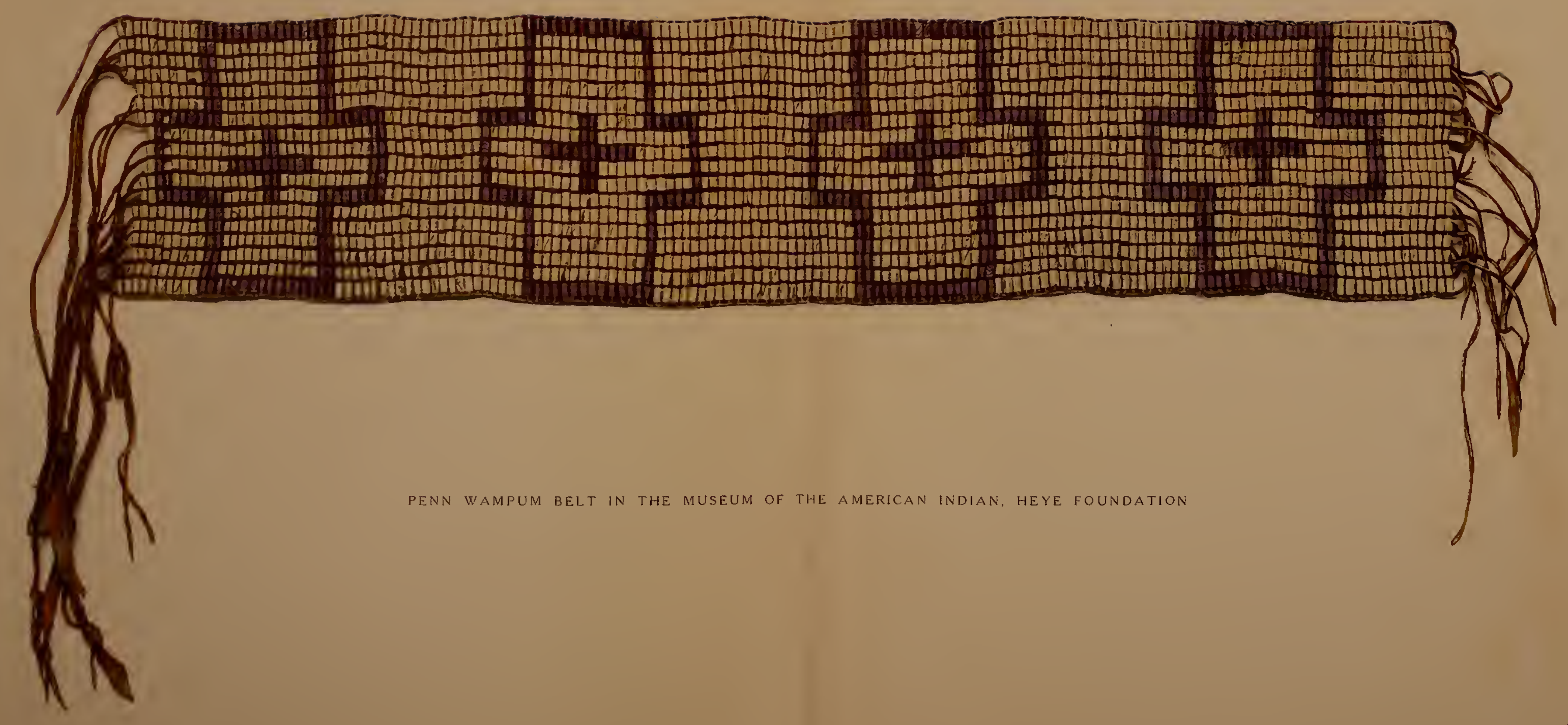





\section{THE PENN WAMPUM BELTS}

chiefs proved to be an absolute contradiction. They stated that the larger figure was that of the Indian, the projection on his head representing his "feather," and the smaller one the white man. They also commented on the relative demeanor of the two, indicated by the proportions of the bodies and their attitudes, saying that at the time the belt was made the Indian would have been the stronger, and the white man the recipient of his hospitality and protection. One is strongly inclined, after giving the conflicting opinions due consideration, to regard the latter interpretation as being more valid. Beauchamp subscribed to the same opinion in his monograph on wampum, to which reference has been made. This belt displays three oblique bars in dark wampum across its surface. Chief Sky stated briefly that these were "stamps" or "seals" of validity, meaning that the sentiment indicated by the presence and attitude of the figures was genuinely intended and subscribed to. I must add, however, that before the photograph had been submitted to Chief Sky, Chief Hill had suggested that these bars might have referred to territories under consideration between the Indians and the English. A closer examination of these bars reveals the fact that the one on the extreme right of the belt is bordered by a white edging on one side. The next one to the left has a white edging on one side and half of the other, and the bar on the extreme left has a white edging continuous on both sides. As might be expected, these details are not susceptible of interpretation at this day, when the purpose for which the belt was made rests so long obscured by the lapse of time. And no remarks were offered on this feature by either of the informants.

This concludes the depositions made by the venerable chiefs concerning the meaning and function of these remarkable belts.

Let us turn now from the discussion of these specific objects to a more general consideration of the problems revived by their contemplation.

Most of the pictorial representations shown on the wampum belts of the Iroquois appear with frequency in the pictographic art of the northern Algonkian, often with the same interpreted significance. Thus the straight parallel lines are, in the symbolism of both cul- 


\section{THE PENN WAMPUM BELTS}

tures, a representation of "roads" or "paths"; the graphic portrayal of two human figures holding hands, or with hands connected, is as much Algonkian as it is Iroquoian, and appears more than once in wampum belts attributed not only to the Delawares but to the Six Nations Iroquois and the Huron. This is a common pattern in Algonkian pictography, its connection in all being "friendship." One could cite other instances, by no means rare, where the symbolism in wampum belts exhibits its connotation, possibly to be regarded as a genetic one, with realistic and symbolic art in the North. Yet the development of mnemonic symbol writing among the Iroquois and their political affiliates, the Delawares, who were at times both their opponents and imitators, is undoubtedly an issue from the advanced culture spirit of the former, and until we can find historical or ethnological proof of its derivation from an older Algonkian art, it will have to stand as such. The motive of wampum belt symbolism in political negotiations among the eastern Indians is then undoubtedly an Iroquoian conception, brought forth by the inventive genius of a people who manifested their progress in many directions. Nevertheless, it should not be overlooked that the actual belts under discussion are the products of the Delawares, an Algonkian people, and that our brief study is one which, for the present, is intended only to contribute something toward the understanding of negotiatory documents of this single ethnic group. There is good evidence that the acquisition of picture writing, so general to the Algonkian of the northern, eastern, and central regions, was a property shared also by the Delawares; and so we have some reason for regarding the whole phenomenon, whether produced in wampum-belt symbolism among the Iroquois or the Delawares, or among the tribes of the Wabanaki confederacy of Maine and the maritime provinces of Canada, as part of the general culture complex of the East. The priority of Algonkian peoples in the region and the little doubted and general distribution of pictorial and symbolic art in the whole area, leave one impressed with the possibility of an Algonkian base for the art concept and an Iroquoian setting for its development, its promotion, and expansion through political negotiations. It is not 


\section{THE PENN WAMPUM BELTS}

without significance, moreover, that we look in vain for a similar development in the latter respect among the Powhatan tribes of Virginia, who were also Algonkian in language and culture, and, turning to the North, that the same are absent among the Algonkian groups in Labrador and the Hudson Bay territory, where, too, Iroquoian influence does not seem to have affected native culture. Nor do we encounter wampum ceremonies or documents among the distant Cherokee, again of Iroquoian linguistic affinity.

Comparing the wampum belts, supposedly of Delaware origin and attributed to the diplomatic contact between William Penn and the Indians, some general resemblances stand forth, suggesting that some standardization in form and symbolism had come to be characteristic of the Pennsylvania localities. One feature to be remarked is the occurrence of a white background as a foundation for most Delaware wampum belts. All three belts ascribed to the negotiations of Penn show this peculiarity, and so does a Delaware belt obtained by Harrington from the Canadian branch of this tribe. The same is true of several other Delaware belts in the collection of the Museum. Another analogy will be found in their relative width, the two belts in this Museum having fifteen and eighteen parallel rows of beads, and the one in the collections of the Historical Society of Pennsylvania having eighteen. A comparison of these with the wampum belts retained by the Six Nations, shows the latter to be generally narrower and to be less often constructed with a white background. Possibly some deductions of historical significance may be made from this circumstance of the white background, based on the relative position of the two peoples-the Delawares on the one hand generally appearing as supplicants for peace and protection, the Six Nations on their part as aggressors and overlords. The symbolic value of peace has generally been assigned to the white wampum belts by those who have contributed to our information on the subject, and in these cases the base construction may be adhered to, since the peaceful intentions, at least, of Penn and the Quakers toward the Delawares need hardly be doubted. Nevertheless, the suggestion of the Six Nations wampum readers, already mentioned, bringing forth 


\section{THE PENN WAMPUM BELTS}

the analogy between the white background and the "parchments" of the English, cannot be lightly passed by. It seems to be another one of the accumulated evidences of European stimulation along lines of political culture. That the eastern tribes intentionally imitated the color of parchment in making the white surfaces in the background of wampum belts would be stating a likelihood in terms perhaps a little too dogmatic, but that they came to see the association with the idea of paper or parchment, upon which symbols were inscribed by Europeans, and their own white surfaces in the wampum belts, is hardly to be questioned with our native testimony from the Iroquois wampum readers in mind.

We have hitherto been considering a specific region and specific objects. That a wider problem is involved need hardly be questioned. One of the distinguishing features of native Indian culture in northern and northeastern America is the occurrence of nascent systems of writing, conveying and recording ideas of political value by means of pictographic and ideographic symbols. This development has long been known among the Eskimo and the Algonkian, and in particular among the later Iroquoian tribes which inhabited the region immediately south of the latter. The use of pictographic symbols appears over a continuous area embracing these peoples, in which respect they contrast with the culture types southward and westward in North America. What the early relationship of this development may have been is still unknown. It offers one of the problems with which American culture historians still have to deal. Progress, however, in research throughout the northern portion of the continent is exhibiting more and more evidence leading to the impression that the prototype of northern culture may have embraced both Eskimo and Algonkian, and that through the latter certain culture landmarks were passed to the precocious Iroquoian peoples subsequent to their invasion of the North.

FRANK G. SPECK 


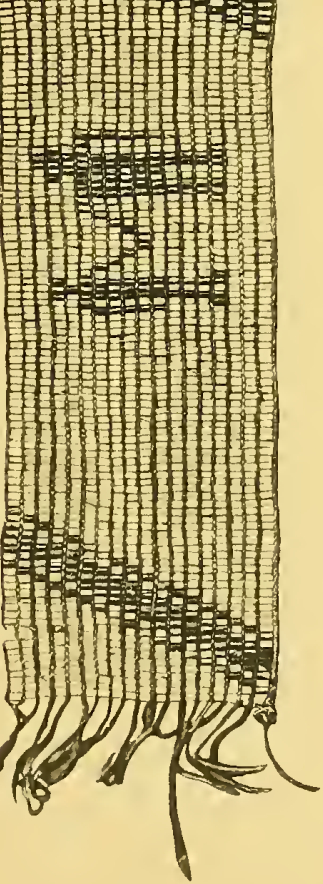

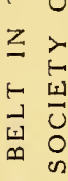

更

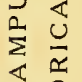

$\geqslant 0$

$z \stackrel{n}{z}$

뇌

I 



\section{The Technique of the Belts}

$D^{5}$

ESCRIPTIONS of the process of wampum belt making among the Iroquois and of the character of the loom employed, as recorded by early observers, are very indefinite. The best account available is that given by Lewis H. Morgan,* the ethnologist, for whom a belt was made at Tonawanda, New York, in I 85 . Although this description is comparatively recent, there is every reason to believe that both the loom and the process of weaving the beads into a belt corresponded with methods and devices of an earlier period. The loom described by Morgan is known as the bow-loom, but one is hardly justified in assuming that this was the only kind employed, for other means of stretching the lengthwise strings, or warp elements, of the belts have been mentioned, although vaguely. Morgan presented the following account:

"In belt making, which is a simple process, eight strands or cords of bark thread are first twisted, from filaments of slippery elm, of the requisite length and size; after which they are passed through a strip of deer-skin to separate them at equal distances from each other in parallel lines. A piece of splint is then sprung in the form of a bow, to which each end of the several strings is secured, and by which all of them are held in tension, like warp threads in a weaving machine. Seven beads, these making the intended width of the belt, are then run upon a thread by means of a needle, and are passed under the cords at right angles, so as to bring one bead lengthwise between each cord, and the one next in position. The thread is then passed back again along the upper side of the cords and again through each of the beads; so that each bead is held firmly in its place by means of two threads, one passing under and one above the cords. This process is continued until the belt reaches its intended length, when the ends of the cords are tied, the end of the belt covered and afterwards trimmed with ribbons. In ancient times both the cords and the thread were of sinew."

*Lewis $\mathrm{H}$. Morgan, League of the Ho-dé-no-sau-nee or Iroquois, Lloyd ed., New York, 1904, vol. II, pp. 54-55. 


\section{THE PENN WAMPUM BELTS}

We thus have a clear idea of the manner in which wampum belts were woven, a process which may be said to have been applied in making all such belts, with perhaps a few minor exceptions. For example, many of the belts were woven on leather thongs, instead of on cords of slippery-elm fiber, as Morgan relates, and other fibers are known to have been used by the Indians for cords and strings, such as dogbane (Apocynum cannabinum), sometimes called amyroot and black Indian hemp; swamp milkweed (Asclepias incarnata), and the hairy milkweed ( $A$. pulchra), also called white Indian hemp; toad flax (Linaria linaria), and Indian mallow ( $\mathrm{Abu}$ -

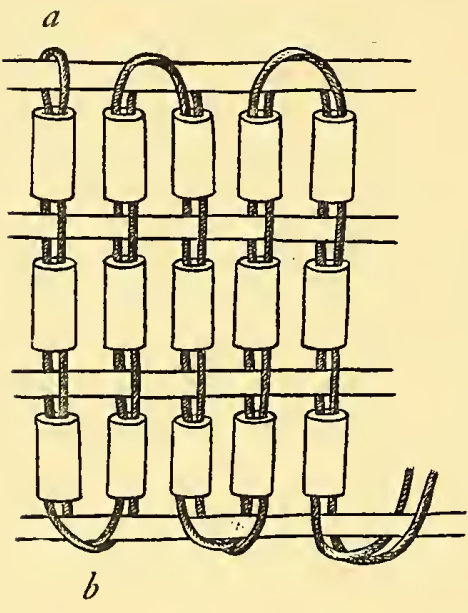

FIG. 1 tilon abutilon), also known as velvet-leaf.

The manner of threading the beads varied. Instead of using a single thread and passing it under the cords and crossing again in the opposite direction above the warp or cords, it is frequently found that the beads were strung on a double thread, as shown in fig. I. The thread is first doubled over a warp-strand on the edge of the weaving $(a)$; the two threads are then passed through a bead; they are then separated and one passed over and one under the next warp-strand, when another bead is threaded on the two strings, which are again separated and passed one above and one below the next warp. This operation is repeated until the width is filled with beads, when the two strings are twisted $(b)$ with one or more turns to cross the weave in the opposite direction, and a bead is placed between each warp-strand. This process is continued until the weaving is completed. A design is incorporated by the insertion of purple and white beads at definite intervals. The ends of the warp-strands, which are usually longer

$$
\text { [18] }
$$




\section{THE PENN WAMPUM BELTS}

than the woven portion of the belt, form a fringe at each end, and sometimes the ends are brought together and braided.

There was no fixed rule for the length or breadth of the belts, which varied from five or six beads in width to as many as the occasion or fancy dictated. The widest belt known is mentioned by Beauchamp (op. cit.) as being fifty beads wide. To give an idea of maximum length one might mention a belt in the Museum of the American Indian, Heye Foundation, which is about sixtysix inches long.

The purple beads were made from the colored lip of the shell of the hard clam, or quahog (Venus mercenaria), while the white wampum was fashioned from the columellæ of the conch. In all the belts the beads are cylindrical, and are fairly uniform in size, ranging from one-eighth to five-sixteenths of an inch in length, rarely more, and about one-eighth to three-sixteenths of an inch in diameter.

The type of beads used in the manufacture of belts was made after the Indians obtained steel for drills from the early Colonists. The metal point was set in the end of a wooden shaft, which was rotated in various ways. One method, it is said, was to roll the drill along the thigh with one hand, while the bead was held against the point of the drill with the other. Another method was to twirl the drill between the hands, a process that would have required another person to hold the bead, unless some device had been invented to grip it firmly.

Implements which greatly simplified the drilling were the bowdrill and the pump-drill. In course of time the demand for wampum increased to such an extent, not alone for belt-making but as a medium of exchange between the Colonists and the Indians, that the manufacture of beads became a thriving industry among the whites in several parts of the New York and New Jersey coastal region. These beads, which became known as Dutch wampum, and counterfeit wampum, were often much longer than those made by the Indians. 


\section{THE PENN WAMPUM BELTS}

An X-ray photograph of a portion of a wampum belt is reproduced in pl. IV to illustrate the drilled perforations. Some of the beads show where the drillings have been made from the opposite ends, while others have apparently been drilled from one end only. There can be no question that a metal drill-point was used, for it would not have been possible to make such perforations with a point of stone. It will be observed that many of the perforations made by drilling from each end have overlapped at the point of juncture because the drill-point was not held true.

The belt illustrated in pl. I is twenty-four and five-eighths inches long, and four and a quarter to four and three-quarters inches wide, the inequality in the width being due to the slightly irregular length of the beads. There are fifteen rows in the width and one hundred and fifty-two beads in the length. Some indefinite markings on the leather thongs suggest that the belt may originally have been one or two beads longer. About fifty beads are missing from the body of the belt; otherwise it is in a good state of preservation. An interesting feature of this belt is that five of the warp-strands are of fiber, while the rest are leather thongs.

The second belt (pl. II) is twenty-five inches long, with varying width, consisting of eighteen rows of beads, aggregating five to five and a quarter inches. In its present condition there are one hundred and fifty-four beads in the length of three rows on one edge and in one row on the opposite edge. From the intervening rows a number of beads are missing, but there are indications on the leather thongs that originally the belt was at least five beads longer. Only two beads are missing from the body of the belt, which in some way must have split and fallen out, as in both instances the supporting threads are entire. The other missing beads are all from one end; the opposite end is complete. At some period in its history this belt was painted red, seemingly with hematite, the pigment still being retained by the leather thongs to a greater or lesser extent, and it adheres also to the ends of some of the beads.

W. C. ORCHARD 


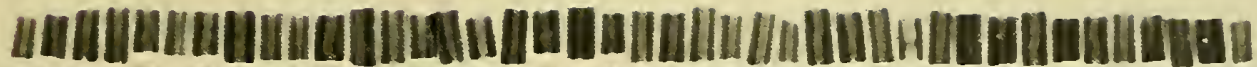

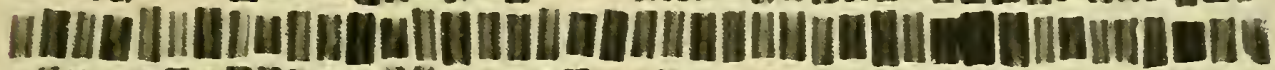 จ|⿴囗丨

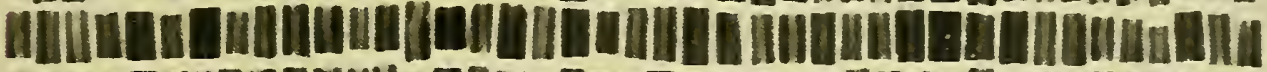

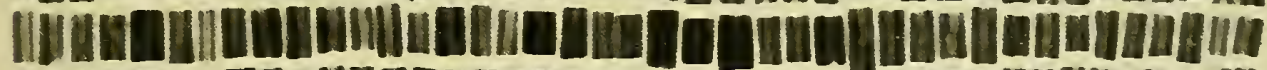

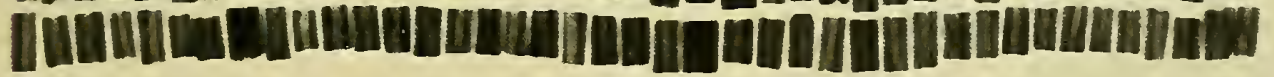

X-RAY PHOTOGRAPH, MADE BY DR. ELSIE FOX,

SHOWING THE PERFORATIONS OF THE BEADS IN A PORTION OF A WAMPUM BELT (EXACT SIZE) 

SMITHSONIAN INSTITUTION LIBRARIES

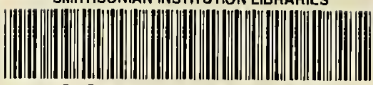

39088011514007 